\title{
CURRÍCULO E DIDÁTICA COMO POLÍTICAS DE SUBJETIVIDADE*
}

\author{
Hugo Heleno Camilo Costa (UFMT) ${ }^{1}$
}

\section{Introdução}

O capítulo resulta de reflexões também produzidas na experiência de ministração do módulo "Currículo e Movimento", em parceria com a Prof.a Dr.a Elni Willms, que foi desenvolvido no curso "Qualificação de Professores da SEMED", oferecido pelo conjunto de professores da UFR. Nele, focalizo a inquietação recorrente pela afirmação de caminhos fixos e seguros para a condução dos processos educativos, para a solução de problemas particulares e genéricos da Educação Básica, para a garantia de formação do sujeito. A expectativa de controle (sobre o conhecimento produzido na escola, os caminhos e futuros para os sujeitos nela envolvidos, as motivações à avaliação, às formas de aprender e ensinar, a atuação de docentes e discentes) assume posição significativa na discussão. Isto não se dá sem que distintos aportes teóricos no campo da pesquisa em educação, bem como o acúmulo de investigações realizadas nas últimas décadas (MOREIRA, 1999; LOPES; MACEDO, 2011; LIBÂNEO; ALVES, 2012), já venham apontando para a pouca efetividade da busca pela precisão e cálculo na relação com o outro, com as culturas, singularidades e contingências, que caracterizam os percursos em educação.

Por esta razão, chamo a atenção para discussões no campo da Didática e do Currículo, por serem campos (e terem seus conceitos e tematizações) invocados com frequência nos debates sobre a produção de conhecimento, formação e justiça social, democracia, entre outros. Focalizo as referidas discussões não com vistas a plasmá-las, mas por considerar potente a concepção de que o diálogo entre elas pode auxiliar na reconceptualiza ção da experiência escolar, da leitura sobre o que pode ser o conhecimento e o sujeito no mundo.

Diferentes discussões voltadas às relações entre a didática e o currículo (MOREIRA, 1999; LIBÂNEO, 2002; SANTOS; OLIVEIRA, 1998; FERRAÇO,

\footnotetext{
*DOI - 10.29388/978-65-86678-68-0-0-f.55-70

${ }^{1}$ Este capítulo é produto do projeto de pesquisa "Sentidos de conhecimento nas políticas de currículo: a Geografia e a Base Nacional Comum Curricular", que conta com financiamento do Conselho Nacional de Desenvolvimento Científico e Tecnológico (CNPq) e apoio PAFiPesqPG/UFMT e PROAP/CAPES.
} 
2012; LIBÂNEO; ALVES, 2012; CORAZZA, 2016) recorrem à preocupação de diferentes autores em incrementar as vias de comunicação entre os referidos campos.

Com vistas a contribuir para este movimento, penso tais campos não como arenas dinamizadas internamente, mas propulsionadas pela sensação de necessidade em responder a anseios sociais mais amplos. Indagações sociais que levam os campos, suas questões e o que consideram como suas atribuições, a constrangimentos em resposta àquilo que lhes imprime à oportunidade de mudança, à produção de verdades contextuais que, quando hegemonizadas por suas comunidades/subjetivações políticas, tendem a constituir marcadores teóricos, conceitos e correntes de pensamento provisórios.

Inspirado na teoria do discurso de Ernesto Laclau, penso os campos em questão como cadeias equivalenciais, sustentadas pela articulação de demandas diferenciais que, ao interpretarem algo como ameaça, constituem-se como comunidades políticas ou, nas palavras de Laclau, como povos. Aqui, o que interessa de tal concepção é a perspectiva de que não há blocos unificados ou fronteiras nítidas no tocante à constituição dos campos em questão, não há univocidade entre determinadas concepções de mundo que julgamos perpassar as preocupações da didática e do currículo. Ao contrário, é colocada em questão a ausência de uma propriedade, de um dado positivo a tais constituições comunitárias, restando a negatividade, a oposição comum a determinada diferença ou nome. A luta por justiça social, o incremento da interlocução com a escola na formação de professores, a busca por produção de situações e/ou culturas inclusivas àqueles que identificamos como à margem da experiência educacional formal, a valorização da escola pública e de seus profissionais, por exemplo, bem podem figurar a miríade de nomes pelos quais contextualmente nos envolvemos em determinada(s) luta(s).

Desenvolver esta abordagem à didática e ao currículo serve, nesse sentido, para supor que se em alguns trabalhos tais campos são vistos como passíveis de encontros (LIBÂNEO; ALVES, 2012), em função da comunicação através de problemáticas entendidas como comuns, isto também pode sinalizar à possibilidade de os lermos como não possuindo fronteiras fixas, mas como construções discursivas articuladas à educação.

Moreira (1999) acena para a possibilidade de uma interferência produtiva entre o Currículo e a Didática, destacando o quanto o fenômeno educacional é amplo e demanda o envolvimento colaborativo de diferentes leituras teóricas. Pondera, ainda, ser limitante a abordagem a questões e/ 
ou situações ligadas à produção de conhecimento, por exemplo, focalizando as oportunidades abertas pelo que pensa com um programa de interferência. O programa proposto instaria em um investimento conjunto voltado para a escola, não com o objetivo de estabelecer novas prescrições e regras a serem seguidas, mas funcionaria como um movimento de aumento do diálogo em torno e com especialistas, docentes, e praticantes escolares.

Em visão distinta a de Moreira (1999), Ferraço (2012) propõe a problematização de trabalhos nos campos do Currículo e Didática, tendo em vista o que denomina por "mundo experiencial" (2012, p.99). Para o autor, os discursos que marcam a complexidade da educação, se interpretados pela lógica das "redes", possibilitam conceber que

[...] as relações entre Currículo, conhecimento e Didática implicam, ainda, envolver nessas redes inúmeros processos, como avaliação, planejamento, gestão, ensino, aprendizagem, entre outros, que configuram os saberes fazeres educacionais. Ou seja, supõe entender que esses processos acontecem todos ao mesmo tempo e de forma inter-relacionada nos cotidianos escolares" (FERRAÇO, 2012, p. 108109).

Para Corazza (2016), teríamos uma dinâmica tradutora entre Currículo e Didática, que seria mobilizada por docentes em seus fazeres criativos e contingentes. A partir do pensamento de Nietzsche, a autora aponta para um horizonte marcado pelo que denomina por vida afirmativa, pulsionada por uma vontade de potência. Defende uma leitura do Currículo como tradutor e a Didática como tradução, não como mais uma proposta teórica para esses campos investigativos, mas como "a corporeidade concreta da vontade dos professores e a sua ética desejante de viver com o caos e seus devires" (CORAZZA, 2016, p.1318). O Currículo e a Didática operariam, simultaneamente, em faixas irredutiveis de leitura de mundo, mas que se interconectam em diferentes momentos do processo educacional.

Segundo a autora, "o professor, a didática e o currículo da tradução consistem em uma determinação do pensamento, que incide sobre fenômenos singulares, como comportamentos e modos de agir, sentir, pesquisar" (CORAZZA, 2016, p. 1321). Processos de tradução formariam processos de subjetivação nas relações constituídas com o conhecimento, com o outro, com os desafios com os quais defrontamos em nossas práticas. Como docentes, seríamos produtores e praticantes da experiência tradutória, na vontade de potência em avançar, fazer e construir, em cada momento de atuação profissional. Corazza (2016, p.1332) assinala também que 
[...] operar com um currículo e com uma didática da tradução serviria para transformar o discurso dogmático da dependência dos professores, que limita o desenvolvimento da teoria educacional sobre uma formação docente, autonomamente criadora; bem como para permitir aportes e abordagens transdisciplinares, que romperiam com o impasse de noções arcaicas e de termos estagnados.

Com as provocações de diferentes experiências aqui entrelaçadas, que estão marcadas por distintas motivações teóricas e, portanto, apontam para abordagens variadas ao mundo, considero como aspecto de relevo destacar a importância da reflexão sobre a ideia de sujeito/subjetividade, que perpassa e pode até ser considerada uma das órbitas aos debates sobre Currículo e Didática.

Por este motivo, chamo a atenção para uma leitura de sujeito que tende a ser concebida no horizonte moderno e iluminista. Uma leitura subjetiva que, em diferentes abordagens teóricas dos campos em questão, tende a ser delineada sob o olhar estrutural.

Está para além dos limites deste texto uma revisão teórica aprofundada de cada momento do pensamento didático ou curricular, bem como cada ocasião de declarada confluência entre os campos. Proponho a elaboração de uma costura que perpasse a possibilidade de operar uma leitura crítico-estrutural mais ampla, precisamente do que Derrida (2001) denomina como metafísica ocidental, para além de um estruturalismo autonomeado, através do qual julgo se viabilizar a projeção subjetiva, e que tende a ser reiterada em diferentes momentos, nuanças e marcas dos pensamentos didático e curricular. Pondero ser igualmente importante a oportunidade de pensarmos, por vias pós-estruturais, uma leitura de subjetivação como precipitação contingente e provisória, como identificação na luta política em que se constitui o currículo como espaço-tempo de fronteira (MACEDO, 2006), como produção discursiva (LOPES; MACEDO, 2011).

\section{Sobre o olhar estruturante}

Para autores como Burity (1997) e Peters (2000), que discutem a assimétrica construção teórica do que chamamos pós-estruturalismo, o que interpretamos como movimento teórico consiste em uma dinâmica crítica aos marcos de uma metafísica da presença, que tende a coordenar diferentes construções teóricas de preponderância no ocidente. Desta forma, o 
marxismo em suas diferentes leituras, a fenomenologia, tradições da psicanálise, da psicologia, o estruturalismo em suas diferentes facetas (linguístico, cultural, psíquico), o humanismo, a hermenêutica, são colocados sob a suspeita de uma atenção pós-estrutural, que tem seu foco voltado para todo um movimento crítico-estrutural que tende a ocorrer na tentativa de assegurar a estruturalidade da estrutura (DERRIDA, 2011).

Ainda que diferentes perspectivas teóricas lidas como tradicionais e críticas embatam entre si, tendem a manter uma circunscrição estrutural (econômica, subjetiva, humana, social, cultural, linguística e/ou mental) como forma de controle das visões sobre o mundo, sobre o sujeito no mundo. Com isso, é apoiada a busca pela "melhor" compreensão de um contexto fechado para, então, ponderar sobre as possibilidades operacionais do sujeito frente a tudo o que o antecede e o condiciona.

Segundo Peters (2000), uma visão estrutural é referente a toda forma de reflexão que opere a partir de verdades fundantes, fundamentais e universais, realistas e racionalistas, marcadas por binarismos. Esta estrutura centrada, sob o crivo de autores considerados pós-estruturalistas, como é o caso de Jacques Derrida, passa a ter indagada sua afirmação estrutural e ideia de centro. Em trabalho de desconstrução de marcadores de um estruturalismo, Derrida (2011) argumenta que a busca pela instituição de um centro diz respeito à busca pelo controle e poder de limitação de seu próprio jogo. Com esta crítica, o filósofo concebe os movimentos em defesa do estruturalismo como tentativa de detenção dos acontecimentos ${ }^{2}$. Para o filósofo, a estruturalidade vindicada pela estrutura sempre se viu neutralizada, embora nunca tenha deixado de operar.

Segundo o filósofo (DERRIDA, 2011), a redução a que se propôs a neutralidade não deixou, em momento algum, de mobilizar esforços para sustentá-la como uma origem fixa, um ponto de presença. Sendo, portanto, capaz de produzir sentidos com vistas à significação do mundo por ela estruturado e, simultaneamente, não só orientar, ponderar e "organizar a estrutura - não podemos efetivamente pensar uma estrutura inorganizada -, mas, sobretudo levar o princípio de organização da estrutura a limitar o que poderíamos denominar jogo da estrutura" (DERRIDA, 2011, p.407- 408). Para o autor, a vigia do "centro" da estrutura tem por objetivo a orientação e embasamento de uma verdade estrutural e a manutenção da coerência do sistema, o que permite controle e, nesse sentido, o estabelecimento dos

\footnotetext{
${ }^{2}$ Para Derrida (2004), o acontecimento é o que sucede e, ao se fazer, surpreende e suspende a compreensão, as estratégias de controlar o que não se conhece. $O$ acontecimento é, a priori, aquilo que não se compreende, que não se conseguiu prever, que irrompe e se dá.
} 
limites fundamentais ao pleno funcionamento do jogo dos elementos internos à estrutura total.

Entretanto, o centro não é o centro e o conceito de estrutura centrada, ainda que espelhe e aspire à própria coerência, é per si contraditoriamente coerente. A busca pela coerência no campo da contradição, acrescenta Derrida, expressa a força de um desejo. A ideia de estrutura centrada é, então, a concepção de um "jogo fundado" (DERRIDA, 2011, p.408, grifo do autor), sustentado em uma imobilidade fundante e uma certeza calmante, ela mesma subtraída ao jogo. Tais certezas e estabilidades ilusivas oportunizam o domínio da angústia que decorre de certa maneira de estar "implicado no jogo, de ser apanhado no jogo, de ser como ser logo de início no jogo" (DERRIDA, 2011, p.408).

Ao ponderar que o centro se furta à estrutura que nele se baseia, Derrida assinala que o centro pode estar simultaneamente dentro e fora da estrutura, recebendo distintos nomes (de início ou fim) e significados com indiferença, e que as repetições, substituições e suplementações transformadoras, são sempre "apanhadas numa história do sentido - isto é, simplesmente uma história - cuja origem pode sempre ser despertada ou cujo fim pode sempre ser antecipado na forma da presença" (DERRIDA, 2011, p.408).

Com esta visão, Derrida pondera que a história da ideia de estrutura precisa ser tomada como uma série ou conjunto de substituições de centro para centro, um "encadeamento de determinações do centro" (DERRIDA, 2011, p.409). Nesse caso, o que noutro momento se poderia pensar ou chamar por centro, pleno e gerador de coerência, nada mais é do que um ponto vazio cujo preenchimento se dá provisoriamente, através do recebimento contínuo de diferentes formas e nomes. A forma matricial do centro, segundo o autor, seria a determinação do ser como presença no sentido mais amplo do termo, do mesmo modo como os mais diferentes nomes do fundamento (deus, essência, estrutura de classe, consciência, sujeito ou existência) sempre pressupuseram, sem variação, uma presença.

Segundo o filósofo, a ruptura do acontecimento da estrutura é promovida desde que se passou a ser pensada, repetida. Os processos de significação, legionários do deslocamento e da substituição, sustentam o anseio pelo centro da estrutura, por uma presença da verdade e da orientação que nunca foi ela mesma, em propriedade, que "sempre já foi deportada para fora de si no seu substituto" (idem, p.409). O centro é como função, um lugar onde infinitamente é feita a substituição dos signos. Quando o centro deixa de ser, está ausente como origem, tudo, segundo Derrida (2011), se 
torna discurso: sistema no qual o significado originário, transcendental, nunca está fora de um sistema de diferenças. A ausência desse tipo de significado (transcendental, originário ou central), dilata indefinidamente o campo e os jogos de significação.

Para Derrida, a construção deste descentramento não pode ser atribuída a um acontecimento, regra, doutrina ou autor específico, sequer seria possível atribuí-lo a um rótulo teórico, mas este movimento pertence "à totalidade de uma época, que é a nossa, mas ela sempre já começou a anunciar-se e a trabalhar" (DERRIDA, 2011, p.410). O pensamento em torno do que estou considerando pós-estruturalismo não deve, assim, ser interpretado como uma sucessão, ou mesmo reação, na forma como agimos na relação com a estrutura. Se concordamos com Derrida (2011), não interessa pensar que o movimento pós-estrutural é uma nova forma de atuação, um momento de revelação sobre nossa condição, desvelamento de uma verdade. Se operarmos desta forma, arriscamos cair na mesma armadilha de considerar que encontramos o centro e ele já não nos oprime, por que agora conseguimos controlá-lo.

O pensamento derridiano projeta a leitura de que, junto à pretensão de estruturalidade e centro organizador da estrutura, sempre já estivemos operando a desconstrução deste centro que nunca foi outra coisa senão sua substituição indefinida. Com isso, Derrida pondera que o poder de influência, de exercício de poder, de poder produzir sentidos sobre o centro, não só não está concentrado em um centro imaginado (agora descentrado), como faz da própria ideia de estrutura uma ficção, haja vista que se os processos de significação produzem centros contingentes (pensemos em contingências de longa duração, hegemonizadas, tais como as correntes teóricas tradicionais e críticas que se tensionam nos campos da didática e do currículo), o centro está sempre por vir a ser, a ser decidido.

\section{Currículo e didática como textos sob tradução}

No livro Teorias de Currículo, Lopes e Macedo (LOPES; MACEDO, 2011, p.37) introduzem a ideia do currículo como "simplesmente um texto", de modo a pensá-lo como extrapolando os pressupostos inseridos por perspectivas crítico-estruturais, que tanto marcam o campo do currículo como o da didática (SANTOS; OLIVEIRA, 1998), conferindo instabilidade aos elementos que sustentam as teleologias e certezas históricas sobre o funcionamento da política e, por conseguinte, da sociedade. Nesse movimento, Lopes e Macedo convidam, através de densa 
argumentação, ao abandono da noção de estrutura e propõem à recondução da discussão pela linguagem.

Para Lopes e Macedo (2011), a compreensão do currículo pelo viés pós-estrutural não implica abandonar as marcas de contribuições do estruturalismo, mas, ao contrário, se aproximam no que diz respeito à centralidade conferida à linguagem como meio de compreensão do social. Como consequência dessa releitura da linguagem, agudiza-se a crítica ao projeto moderno de conhecimento e de subjetividade, uma vez que pontua a impossibilidade de pensar em um conhecimento sobre o mundo e o sujeito. Essas marcas de um pensamento moderno, segundo as autoras, pautam, ainda que em preocupações e enfoques diferenciados, distintas correntes do pensamento curricular, desde os estudos cunhados pelo eficientismo e tecnicismo, passando pelo pensamento de autores considerados progressistas, crítico-reprodutivistas, neomarxistas, envolvidos com a Pedagogia Libertadora e Libertária.

Com a crítica ao estruturalismo em sua desconsideração de que a própria estrutura é uma produção da linguagem, o pós-estruturalismo coloca que a compreensão da estrutura como fundamento conduz à possibilidade de que se reative as criticadas perspectivas realistas (LOPES, MACEDO, 2011). Nesse sentido, a linguagem é reeditada, deixando de ser vista como transparente, como representante da realidade, e passa a ser interpretada como aberta aos processos de significação. $O$ significante não detém significado, mas é contingencialmente significado. Segundo Lopes e Macedo (2011), o que possibilita sua significação provisória é o seu caráter diferencial na relação com outros significantes constituintes do sistema linguístico. Ou seja, determinado termo não possui um significado correspondente a algo que existe na realidade. Em cada momento de suposição de um significado, estamos criando um significado para o significante (LOPES, MACEDO, 2011) e isso é o mesmo que a busca pela construção de um centro, como pontua Derrida (2011).

A atitude pós-estrutural insere a perspectiva de que não há relações estáveis e previstas entre significantes, não há significantes imanentes, o que impossibilita a determinação "do" significado. Segundo Lopes e Macedo (2011), um significante remete a outro continuamente. O significado de um significante passa a ser pensado como flutuante e, portanto, seu sentido só pode ser cogitado no âmbito de uma formação discursiva histórica e socialmente contingente, o que, por sua vez, projeta o questionamento sobre quais fatores e condicionantes sócio-históricos possibilitam que determinado discurso construa a realidade em determinado momento. 
Este questionamento, posicionado como problemática latente para esta visão de mundo, de currículo, chama a atenção para os processos de negociação que, ajustados contingencialmente, viabilizam a que dado discurso ganhe maior relevância em determinado momento contextual, em detrimento de uma miríade de outras possibilidades. Tal concepção de discurso é teoricamente imbricada ao poder. Ou seja, o conhecimento é pensado como parte do discurso. E este último passa a ser entendido como função do poder, estando afastado, portanto, do sentido moderno de que o conhecimento é poder para quem o detém. Pensar o discurso por esta via é conceber toda produção de sentido como poder (LOPES, MACEDO, 2011).

A visão pós-estruturalista, abordada por Lopes e Macedo (2011) no campo do currículo, desloca o questionamento sobre o que é (o aluno, o currículo, a didática, a disciplina ou a experiência escolar) para a investigação de como os sentidos, produtores de discursos, se intersectam na articulação política e constroem determinada ideia de mundo, de fundamento, de centro, para uma sociedade ou comunidade específica. Esta performance discursiva é que, segundo as autoras, torna possível a ideia de sociedade, de aluno, currículo, conhecimento, justiça social ou disciplina escolar. O currículo, então, não existe como objeto da realidade, mas é uma construção constante, que decorre das substituições, traduções e iterações diferenciais produzidas pelas tradições curriculares que, também, não são outra coisa que não construções pretendidas à verdade, constituição de um centro. $O$ fato de dado discurso sobre o currículo, assim como a tudo o que se desdobra na relação com ele, ser aceito como tradição curricular, como uma verdade em dado momento, como centralidade, e que passa a figurar no cenário do campo curricular, não é uma possibilidade dada a qualquer afirmação.

Desta maneira, uma tradição, uma forma de pensar o currículo legitimada só o é como tal quando hegemônica (LACLAU, 2011). Aqui, a retomada dos pressupostos de verdade, dos pontos de partida que se pretendem fundamentais, deve se imbuir de uma atitude desconstrucionista voltada a questionar, especificamente, os processos de imposição e sustentação de tais tradições (LOPES, MACEDO, 2011).

Currículo e didática, pensados como prática discursiva e, portanto, como prática de poder, poder de significação, de modo contingencial e indefinido, constroem a realidade com seus pretensos mecanismos de funcionamento, de regulamentação e limitação. Como tentativa de ser estrutura, o processo de significação, de estabilização de tudo o que dizemos que é currículo, não cessa. A reiteração da (des)estruturalidade do currículo leva à 
disseminação (DERRIDA, 2001) contínua e, assim, à produção de significados que, mesmo visando a apoiar determinado discursos, os suplementam, fazendo-os outros.

O fazer-se curricular e didático, pensados como práticas discursivas, abre mão de qualificações outras, pois como texto em processo influencia diferencialmente o leitor/interlocutor que o (re)cria. Esta perspectiva se constitui como convite permanente à revisão dos discursos que produzem sentidos aos referidos campos. Esse caráter contextual e sobredeterminado de pensar o currículo como decorrente de leituras e suplementações criativas da história, da tradição, emergências sociais, demandas, traduções, traições, disrupções e sensações de continuidade, inseridas pela aspiração à completude de sujeitos que só são porque querem ser sempre, introduz, dentre outras vias, a premência de um trabalho de tentativa de construção de um (des)centro reconhecível do que é o currículo.

Em acordo com esta leitura, chamo a atenção para a perspectiva de currículo como espaço-tempo de fronteira, proposta por Macedo (2006), através da qual pensa a produção curricular como negociação de sentidos diferenciais implicados nas disputas pela hegemonia do saber e ser curricular. O que traz, como desdobramento possível, a interpretação da didática como podendo ser compreendida por sua discussão curricular, haja vista a proposta, implícita, de ruptura com limites fixos entre possibilidades de reflexão sobre a potencialidade de produção de sentidos para e na educação.

Com base em revisão das produções sobre currículo no Brasil, Macedo $(2006$; 2012) argumenta que grande parte das discussões orbitam na ideia do currículo como mecanismo de transmissão de conhecimentos externos à escola, como seleção de uma cultura legítima. Ressalta que tanto em perspectivas tradicionais como críticas e pós-críticas, a cultura continua a ser discutida como objeto/conteúdo de ensino. A autora analisa as perspectivas presentes em diferentes vertentes teóricas e defende que a cultura foi, por determinado período, vista como um repertório de sentidos partilhados, produzidos em espaços externos à escola (MACEDO, 2006, p. 101). Para a autora, na busca pela superação de tais perspectivas, outros autores como Young, Whitty e Goodson, passaram a dar maior centralidade aos processos cotidianos desenvolvidos no ambiente escolar e a conceber a produção da cultura como decorrência da atividade de professores e alunos.

Tais concepções, marcadas por uma bipolarização entre currículo como prescrição/teoria/proposta/formal e como prática/em ação/cotidiano/dinâmico, são vistas por Macedo (2006) como preocupantes, pois ape- 
sar de contribuírem para novas concepções sobre o currículo, pouco avançaram nas relações entre elas, fazendo com que tal ampliação se caracterize pelo somatório de dimensões não articuladas.

Macedo (2006) pontua que, embora seja perceptível a mudança rumo à dimensão vivida do currículo, não houve ruptura com a noção de currículo como prescrição. Para ela, na produção curricular brasileira, podese matizar dois grandes blocos: de um lado, uma tendência em conceber o currículo como pré-ativo, como proposição, como receita; de outro, há a ideia do currículo como algo produzido no/pelo cotidiano. Desta forma, fica a tensão entre as visões do "poder dos poderosos", do Estado, da prescrição; e a visão do "poder dos subalternos", da comunidade escolar, do cotidiano, com sua habilidade para subverter por resistência e/ou negligência o que "vem de cima".

É insuficiente, segundo Macedo (2006), enfatizar o currículo como prática para que se possa compreendê-lo como um espaço-tempo de produção cultural, como algo que está sendo, como dinamismo e produção via relações hegemônicas provisórias. Para que se possa dar conta da compreensão curricular nesse sentido, a autora defende a necessidade de pensar o currículo como espaço de produção cultural, sem que se faça distinção entre as dimensões formal e vivida. Nessa discussão, propõe o currículo como um espaço-tempo de fronteira entre saberes, através de uma concepção de poder mais oblíqua (GARCIA-CANCLINI, 1998).

O currículo, portanto, deve ser concebido como práticas discriminatórias, por meio das quais a diferença é produzida, como a "negociação de posições ambivalentes de controle e resistência" (MACEDO, 2006, p.105). E continua, ao argumentar que o currículo deve ser visto como cultura; não uma cultura, com repertório de sentidos partilhados, mas como "lugar de enunciação" (MACEDO, 2006, p.105). Este lugar de enunciação passa a ser visto como um híbrido em que as culturas impuras passam a negociar com a diferença.

Importa enfatizar que, para Macedo (2006), a noção de espaçotempo de fronteira implica uma concepção curricular capaz de operar com a ideia de interação de culturas, sem que haja hierarquização entre as mesmas. Ao partir da perspectiva de que as culturas já híbridas interagem com outras, gerando outros híbridos, a autora insere a noção de impureza como condição para a não estratificação entre os elementos. Assim, não há um original que busca saturar o outro, mas processos de disputas por hegemonia de uma ou outra perspectiva, demanda, ideia. Sem a busca pelo estabelecimento de um início ou fim, Macedo (2006) propõe colocar os matizes 
das mais distintas possibilidades de tentativas de representação sob o olhar da desconfiança. Concordo com a autora ao argumentar que estar na fronteira (onde se está! Não é um lugar para onde se vai) é viver no limiar entre as culturas, "um lugar-tempo em que o hibridismo é a marca e em que não há significados puros" (MACEDO, 2006, p. 106). Hibridismo também considerado por Laclau (2011) como não sendo um fenômeno marginal ou deletério, mas o próprio terreno em que as identidades políticas se produzem na atualidade.

Pontuo que atuar com tal concepção implica ler a fronteira, não como divisão de territórios fixos, delimitados, em que os ali chegados possuem uma origem, vêm de um lugar o qual representam, e que lhes adjetiva. Neste espaço-tempo fronteiriço, todos se produzem e são (d)ali. Se são híbridos, logo impuros, não vêm de lugar algum, mas via interação cultural/discursiva/textual estão em constante processo de identificação, constituindo-se como sujeitos nos mais diferentes espaços sociais, na luta política (LACLAU, 2006). Se não vêm de lugar algum, só se pode ser da própria fronteira que, desta forma, passa a ser um lugar que nunca é o mesmo, na medida em que deixa de ser em função do próprio movimento de subjetivação e significação da e na fronteira.

Segundo Macedo, a "negociação dos pertencimentos é sempre um processo contingente e de transferência de sentidos" (MACEDO, 2006, p.110). Este processo, contingente e instável, que se desenvolve na negociação dos sentidos de pertencimentos e de significação, incide na impossibilidade de se manter a fixação da escrita/textualização/espaçamento do mundo, da luta política, da significação da educação, da própria fronteira.

\section{Considerações finais}

Compreendendo a ideia de currículo como produção discursiva, como espaço-tempo de fronteira cultural, constituída pelas motivações diferenciais operantes na construção da torre de babel curricular, temos que as visões atribuídas ao currículo, à didática, à escola, a professores e alunos, nada mais são do que significados imputados àquilo que sempre é outra coisa. A perspectiva de currículo aqui projetada tenta se opor às ideias monolíticas de estrutura, de centro, verdade e sujeito, que pretendem saturar o nome de uma verdade.

Defendo que o que quer que estejamos chamando de currículo, didática, prática, sujeito, deve ser considerado como sempre em aberto à sig- 
nificação pelo outro, à ruptura causada pelo outro, ao acontecimento de um novo significado, que reordene a política, a experiência.

Pensar o currículo por essas marcações pós-estruturais pode levar a que a abordagem sobre a política seja repensada também por estas perspectivas. Nesse sentido, uma reflexão sobre a política curricular, entendendo-a como o efeito produtor do currículo, deve ser redimensionada e nos lançar novamente na fronteira curricular. Pensar a atuação política como jogo de linguagem, como negociação interpretativa, como significação do que nos produz em dada fronteira, como o que mobiliza ao envolvi mento, implica, como não poderia deixar de ser, um trabalho de significação do que entendo por subjetividade, escola, política curricular, didática.

Ser fronteiriça é a condição que cabe a toda identificação. E nesse movimento a prática não pode ser vista como algo restrito a determinado âmbito (escolar ou acadêmico, de professores e alunos, ou pesquisadores), mas como toda produção de sentido que dinamiza a fronteira curricular em que se constitui a própria possibilidade de significação de si na relação com o outro. A própria ideia de prática, aqui pensada como prática discursiva, não pode estar circunscrita a uma identificação a priori, mas diz respeito a todo ato de poder que dado envolvimento (curricular, didático, se assim quisermos colocar) detona.

Seguir nessa direção não é defender que tudo é possível e válido de qualquer maneira, mas que em contextos que também não podem se fechar sobre si mesmos, contingencial e provisoriamente, decisões/práticas discursivas, que estão para além de instituições formalmente nomeadas, se articulam, como diferenças, criando verdades contextuais que, uma vez universalizadas, criam (des)centros gravitacionais, hegemonias. O poder não é de um sujeito encarnado historicamente, proletário, consciente, crítico, dado por uma estrutura que se conhece em seus limites. O poder (de significação) não está associado a um fazer consciente, mas a toda forma de praticar a significação do mundo na relação com uma alteridade radical.

O poder como interlocução, em uma linguagem opaca, para além de boas ou más consciências, com um outro desconhecido, com quem/que não possuímos relações estáveis, mas que se quer conhecer, dominar, controlar. Ao fazer isso, onde quer que se esteja, sempre se pratica a significação do outro, independente de o conhecermos. Responder aos questionamentos na fronteira é condição para subjetivação, para estar e ser poder. 


\section{Referências}

BURITY, J. A. Desconstrução, hegemonia e democracia: o pós-marxismo de Ernesto Laclau. In: OLIVEIRA, M. A. G. O. (Org.). Política e contemporaneidade no Brasil. Recife: Edições Bagaço, 1997, p. 29-74.

CORAZZA, S. M. Currículo e Didática da Tradução: vontade, criação e crítica. Educação e Realidade, p. 1-26, 2016.

DERRIDA, J. Posições. Belo Horizonte: Autêntica, 2001.

A escritura e a diferença. São Paulo: Perspectiva, 2011.

FERRAÇO, C. E. Possíveis tessituras entre currículo e didática: sobre conhecimentos, experiências e problematizações. In: José Carlos Libâneo; Nilda Alves. (Org.). Temas de pedagogia: diálogos entre didática e currículo. 1. ed.São Paulo/SP: Cortez, 2012, v. 1, p. 98-123.

GARCIA-CANCLINI, N. Culturas híbridas: estratégias para entrar e sair da modernidade. São Paulo: Edusp, 1998.

LACLAU, E. Emancipação e diferença. EDUERJ: Rio e Janeiro, 2011.

LIBÂNEO, J. C. Os campos contemporâneos da didática e do currículo: aproximações e diferenças. In: LIBÂNEO, J. C.. Didática: velhos e novos temas. Goiânia: edição do autor, 2002. p. 86-109. Disponível em: http:// gtdidatica.sites.uol.com.br/textos/libaneo.pdf. Acesso em: abr. 2014.

; ALVES, N.G. Temas de Pedagogia: diálogos entre a didática e currículo. São Paulo: Cortez, 2012. v. 1.

LOPES, A. C.; MACEDO, E. F. Teorias de Currículo. São Paulo: Cortez, 2011.

MACEDO, E. Currículo como espaço-tempo de fronteira cultural. Revista Brasileira de Educação, Rio de Janeiro: v. 11, n. 32, p. 285-296, maio/ago., 2006.

. Currículo e conhecimento: aproximações entre conhecimento e ensino. Cadernos de Pesquisa, v.142, n. 147, p. 716-737, set./dez. 2012. 
MOREIRA, A. F. B.. Didática e Currículo. Educação e Realidade, Porto Alegre, v. 23, n.2, p. 11-26, 1999.

SANTOS, L. L. C. P.; OLIVEIRA, M. R. N. S. Currículo e Didática. In: OLIVEIRA, M.R.N.S. (Org.). Confluências e divergências entre didática e currículo. Campinas: Papirus, 1998, v. 1, p. 9-32.

PETERS, M.. Pós-estruturalismo e filosofia da diferença. Belo Horizonte: Autêntica. 